\title{
DAMAGE EVOLUTION FOR REPAIRABILITY OF SUBSTANDARD BEAM-COLUMN JOINTS
}

\author{
Özgür Yurdakul ${ }^{1}$, Ciro Del Vecchio ${ }^{2}$, Marco Di Ludovico ${ }^{3}$ \\ Ladislav Řoutil ${ }^{1}$, and Özgür Avşar ${ }^{4}$ \\ ${ }^{1}$ University of Pardubice \\ Department of Transport Structures, Faculty of Transport Engineering \\ (ozgur.yurdakul, ladislav.routil)@upce.cz \\ ${ }^{2}$ University of Sannio \\ Department of Engineering \\ cdelvecchio@unisannio.it \\ ${ }^{3}$ University of Napoli Federico II \\ Department of Structures for Engineering and Architecture \\ diludovi@unina.it \\ ${ }^{4}$ Eskişehir Technical University \\ Department of Civil Engineering, Engineering Faculty \\ ozguravsar@eskisehir.edu.tr
}

\begin{abstract}
Substandard reinforced concrete $(R C)$ joints often exhibited poor seismic performance even under moderate intensity earthquakes, which is due to the lack of earthquake-resistant design detailing. Premature joint cracking often compromises the seismic performance of the entire building, initiating local collapses or global failure mechanisms. The quantification of the joint repairability in terms of reduction of the structural damage as well as expected economic losses is still a challenging task. This is due to the uncertainties in the assessment of residual and maximum crack widths. This study deals with the evaluation of crack by the increasing drift level. To this end, available numerical and experimental cyclic data on the substandard beamcolumn joints are collected. The variability in material properties is considered and the correlation between residual and maximum crack width is obtained. These data are then used to obtain residual-to-maximum crack width ratio by increasing drift level. The available repairability thresholds are then compared with the residual-to-maximum crack width ratio curve.
\end{abstract}

Keywords: Crack width, Repair, Probabilistic, Beam-column joints, Substandard 


\section{INTRODUCTION}

Existing reinforced concrete buildings designed according to former code provisions lack several earthquake-resistant design detailing. This makes these buildings vulnerable to seismic actions. The poor energy dissipation and sudden strength and stiffness degradation are the main consequences of the brittle failures of such vulnerable structural members. Beam-column joints deserve special interest in existing buildings because they can be the critical and possibly the weakest link according to the capacity design principles or hierarchy of strength considerations [1]. Such an unfavorable seismic behavior of joints obviously compromises the structural integrity of the whole system. Therefore, the experimental performance of the deficient joints has attracted considerable research interest [2-7]. The response of beam-column joints under a multiaxial complex stress field is also reproduced by the computer-aided nonlinear analysis [8-12]. The refined and validated numerical models are also combined with the stochastic approach requiring a solution with randomized material properties to improve the accuracy of the analysis results [13-15]. The repair of deficient joints has attracted considerable research interest [1620]. However, the building repair is usually limited by the high repair cost of drift-sensitive members [21], and massive reconstruction and intrusive repair procedures [22]. Besides, the repair procedure and type are fairly sensitive to damage level (i.e., light, moderate or severe damage). The damage indicators characterizing the severity and extent are usually associated with the crack width for light/moderate damage level and macroscopic concrete and reinforcing bar damage for severe damage state [23-29]. Therefore, the selection of a suitable repair procedure usually depends on damage level and crack width. The evolution of the crack width by the increasing drift level, the correlation between maximum and residual crack width are important parameters in assessing the level of damage (and the repair actions). The effect of randomness at the material level should be also considered when obtaining such engineering demand parameters (EDPs). This study mainly deals with the evolution of crack at imposed drift and residual crack width by the increasing drift level. The residual-to-maximum crack width ratio at imposed drift ratio is obtained to show the crack closure effect. Then, this ratio is compared with current repairability thresholds to obtain proper relationships suitable for onsite engineering applications.

\section{METHODOLOGY}

The deformation limit of serviceability and its corresponding crack width are usually considered as a threshold for the building repairability considering conventional repair actions (i.e., crack filling, concrete patching, or cover replacement). On the other hand, it should not be beyond economical repair. FEMA P-58 [30] specifies a threshold value of 50\% of building cost when contemplating whether a damaged structure should be replaced or repaired. Light to moderate damage can be identified as the threshold for the feasibility of repair. Here, light damage corresponds to hairline cracks or cracks that can be repaired with surface finishing/epoxy resin while moderate damage refers to remarkable wide cracks, concrete cover spalling, local concrete crushing, and reinforcement yielding [30, 31]. The use of fiber-reinforced polymers (FRP) for the repair and rehabilitation of heavily damaged RC members is an efficient solution [2328]. The indicators for the detection of damage at light to moderate damage levels are also identified for in-situ inspections in terms of residual crack width. Therefore, the residual crack width can be useful for the detection of the damage during post-earthquake damage inspections for the feasible repair action. The available standards and guidelines also refer to the use of residual crack width for repairability [23, 25, 27, 32]. On the other hand, special attention should be given to assess the residual crack width as the scatter in the residual crack width is high. 
Note that, Maximum Inter-story Drift Ratio (IDR) is commonly accepted to be a key engineering demand parameter. The residual story drift is also one of the global acceptance criteria for repairability [32], however large variability could be associated to this parameter and residual crack width. Besides, it is more sensitive to hysteretic unloading and reloading response in moderately damaged reinforced concrete plastic hinges [31]. In the case of brittle behavior of joint, limiting the residual displacements (and so the residual crack width) as a means of increasing the probability that the building can be repaired following earthquake ground shaking is also an efficient solution. Therefore, the damage evolution could be represented by the crack width at maximum and residual IDR.

This research proposes relationships between residual crack width and maximum crack width together with the correlation to maximum drift. This allows the reader to obtain the relationship between residual and maximum crack width together with the evolution of the crack width by the increasing drift level. To address this scope, the outcomes of stochastic analyses developed on validated FEM numerical models are used. The substandard beam-column joint specimen with low strength concrete and plain round bar is first tested (i.e., specimen EJ_R) [22]. Then, the progress of crack developments, its patterns, and global hysteretic response is reproduced in ATENA Science [33] finite element method (FEM) software. The modeling approach, the constitutive law of the materials and its parameters suitable for application to substandard beam-column joint, modeling accuracy and effectiveness in reproducing the experimental behavior, modeling advantages-disadvantages, difficulties in the modeling of substandard joints are discussed in detail in Yurdakul et al. [12]. The simulation of the randomness at the material level (i.e., concrete and reinforcing steel) is accounted by computational stochastic mechanics. The mechanical properties of concrete and reinforcing steel are described as random variables to consider the variability in material properties [14]. Thus, the effect of material parameters on the cracking response is found. The residual crack width and maximum crack width at the imposed drift with their scatter are obtained from the numerical analyses. In many cases, the cracking mechanism at the joint back, joint core and interface occur simultaneously. The most critical cases for the most unfavorable situation are taken into account when evaluating the crack width at each location of the joint region. More detailed information about the cracking response can be found in Yurdakul et al. [13].

\section{RESULTS AND DISCUSSION}

The outcomes of numerical analyses in terms of the crack width vs. maximum or residual IDR are reported in Figure 1a and b, respectively. The data can be fitted with a linear relationship with an acceptable level of accuracy. The correlation among datasets (i.e., imposed/residual drift and imposed/residual crack width), referred as the coefficient of determination $R^{2}$ in the graphs is high, demonstrating the accuracy of the fitting. When both imposed and residual crack widths at the interface are considered, a higher scatter in fitting the data can be observed.

As mentioned in the previous section, the uncertainty in the residual crack width is high. Therefore, the reliability of setting a crack repairability limit based on the residual drift (and so crack width) should be further investigated. The correlation between the residual crack widths and maximum crack widths is presented to validate the range of application of the considerations for joint repairability based on residual crack width. For this purpose, the data are fitted with a linear relationship, and the correlation between the residual crack widths and crack widths at imposed drift is obtained for 30 samples (see Figure 2). The graph indicates the correlation at each imposed and residual drift ratio. 

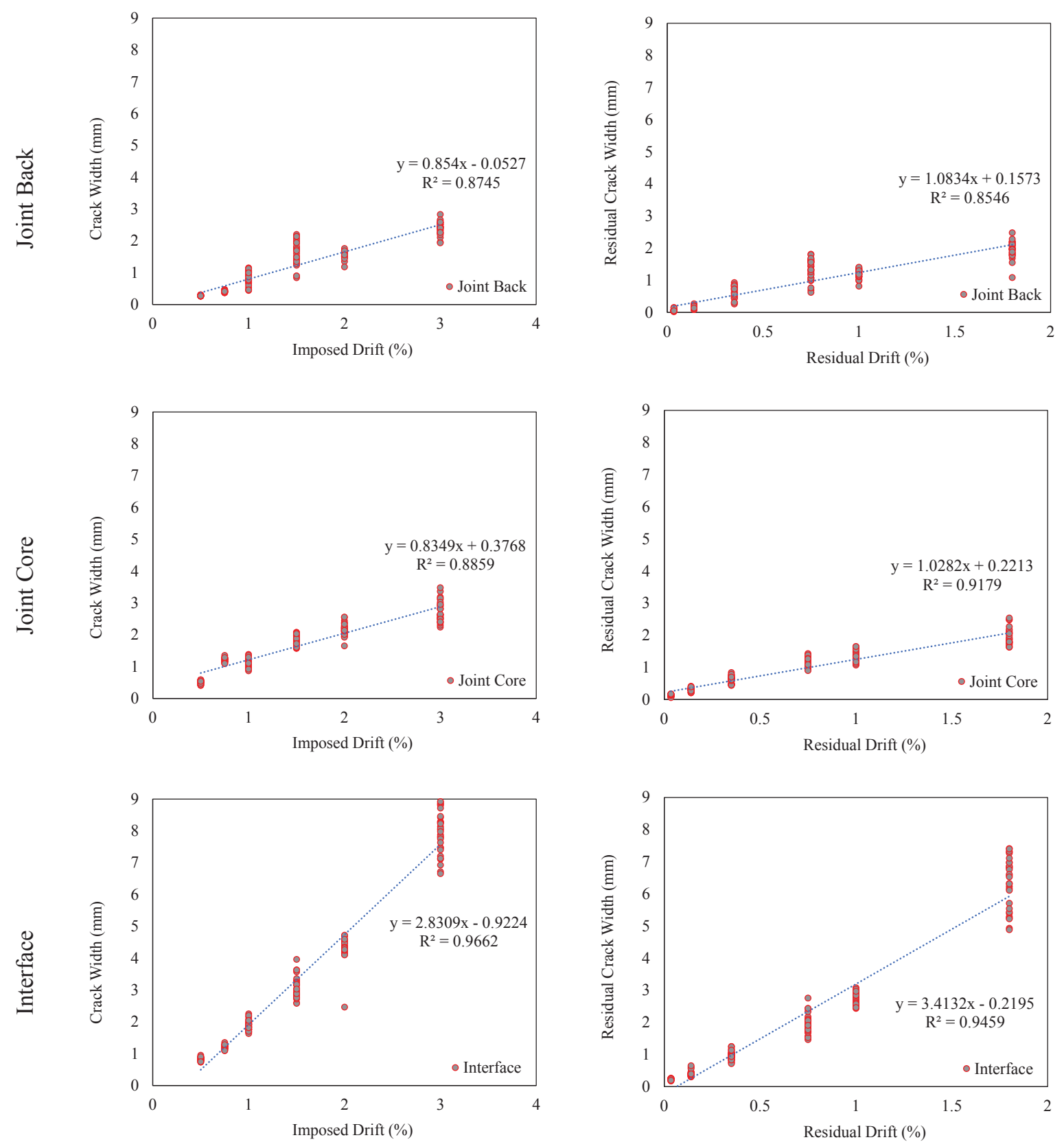

(a)

(b)

Figure 1. Correlation between (a) maximum crack width and imposed drift (b) residual crack width and residual drift (EJ_R) 


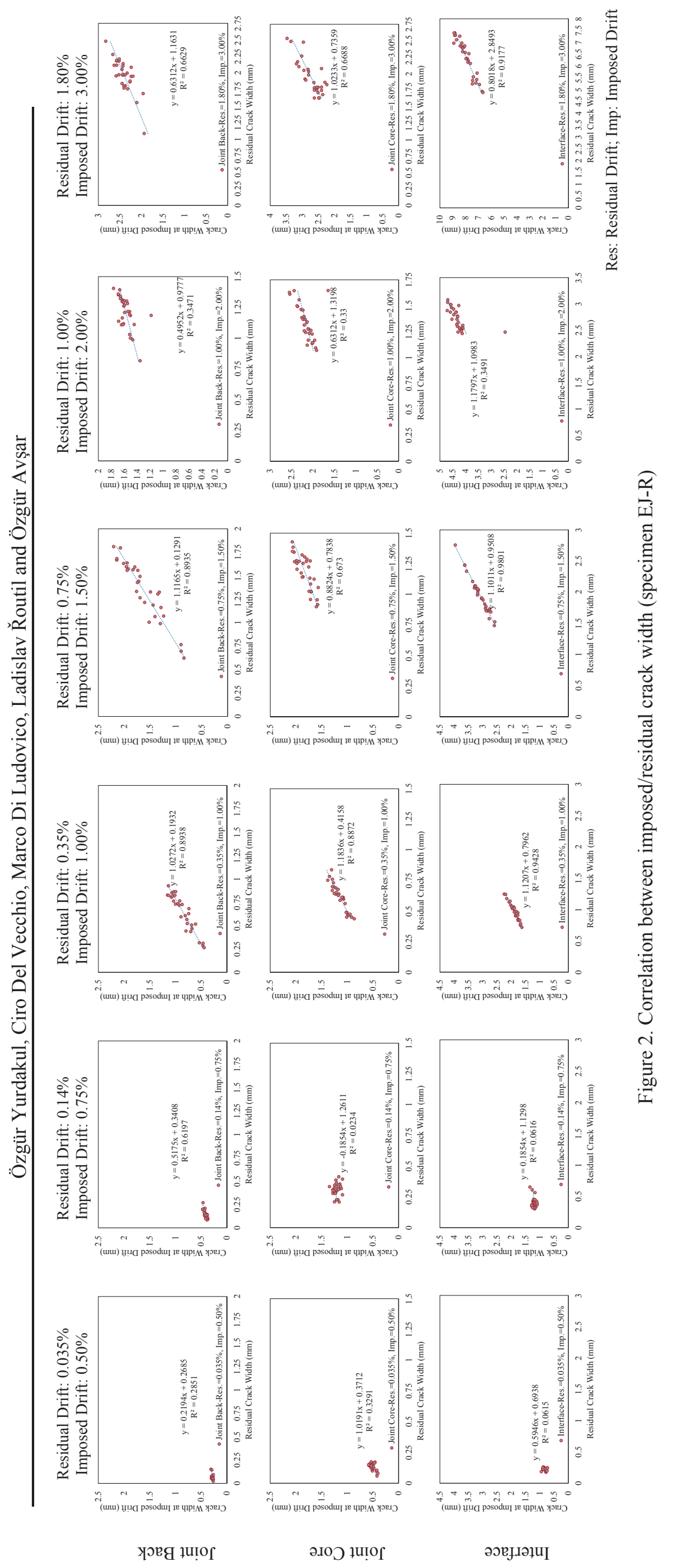


The evolution of the correlation coefficient, referred as a coefficient of determination $R^{2}$, at each drift level in Figure 2 is presented in Figure 3. A low correlation between peak and residual crack width is found at low imposed drifts (i.e., 0.50 and $0.75 \%$ ). This is due to the sensitivity of the crack width to the tensile strength of concrete at low joint shear stress demand [14]. Indeed, a high variability of concrete tensile strength is widely recognized $[34,35]$. The $R^{2}$ values indicate the acceptable level of correlation between the residual crack widths and crack widths at imposed drift at $0.35 \%$ residual drift (corresponding to the imposed drift of $1.00 \%$ ) and $0.75 \%$ residual drift (corresponding to the imposed drift of $1.50 \%$ )). It should be noted that FEMA P58 [30] refers to the residual drift ratio of $0.5 \%$ as a threshold for the feasible repair action. The residual drifts of $0.35 \%$ and $0.75 \%$ are the closest values to $0.5 \%$ residual drift ratio representing the threshold limit as per FEMA P58 [30]. The correlation then drops to a certain level in the subsequent drift levels. This could be due to excessive damage in subsequent drift levels.

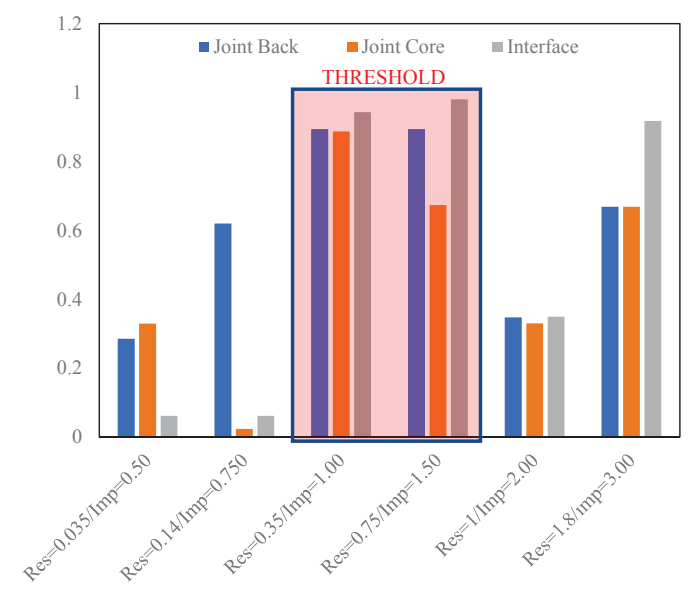

Figure 3. Coefficient of determination $R^{2}$ of the linear fitting of maximum vs residual crack width at increasing drift demand.

The change in the residual-to-maximum crack width ratio by the increasing imposed drift is presented in Figure 4a-c. If one of the parameters in Figure 4a-c is known, the other parameters can be estimated from the presented equations. For instance, the proposed relationships allow the calculation of the maximum crack width by knowing the residual crack width and maximum inter-story drift (that can be estimated with a numerical model). Thus, it allows correlating two of the most important EDP to assess building repairability.

An in-depth analysis of the results reported in Figure 4a-c allows to draw important consideration on the feasible repairability and crack closure effect for RC beam-column joints. An ascending linear trend is followed by a second linear trend with a lower steepness. The change of steepness approximately takes place between $1.00 \%$ and $1.50 \%$ imposed drift. With the less steep curve, the residual-to-maximum crack width ratio gets close to 1.00. Namely, the cracks become large enough, which are not closing, and exhibit large residual cracks. Therefore, the breakpoint of the curve where it changes the characteristics can be assumed as a feasible repairability threshold value. Note that the residual drifts of $0.35 \%$ (corresponding to $1.00 \%$ imposed drift) and $0.75 \%$ (corresponding to $1.50 \%$ imposed drift) are the closest values to residual drift ratio of $0.5 \%$ being a threshold for feasible repair according to FEMA P58 [30]. Overall, the change in the characteristics of the multilinear curve takes place between $1.00 \%$ and $1.50 \%$ drift ratio, being the corresponding imposed drifts closest to the feasible repair threshold. 


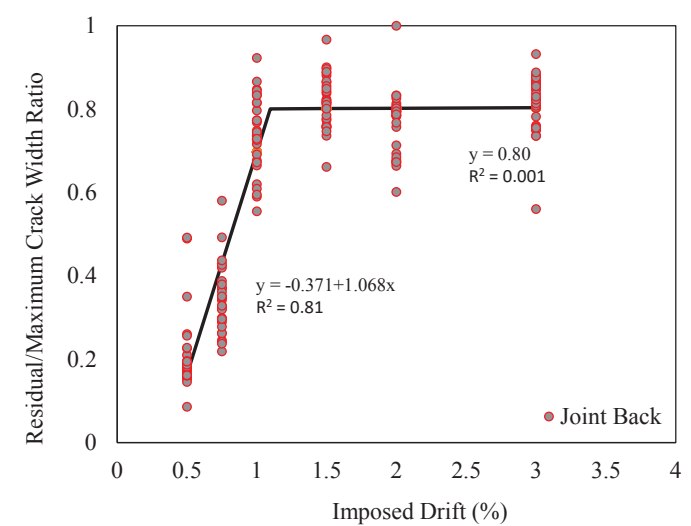

(a)

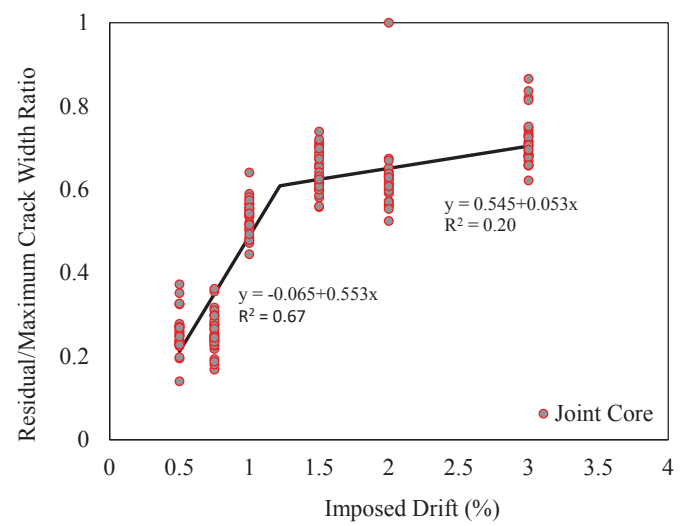

(b)

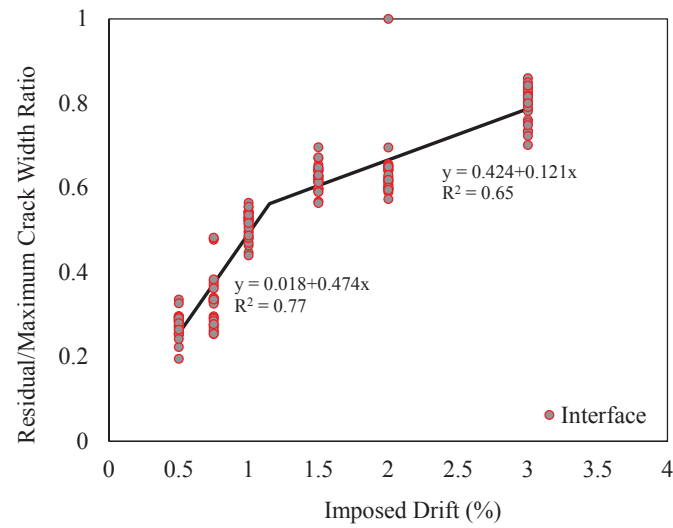

(c)

Figure 4. Residual to maximum crack width ratio at different residual drift levels

The proposed residual-to-maximum crack width curves are compared with each other as well as with the curve available in the literature (Figure 5). The trend of the proposed curve for the joint back crack is far from the experimental observations of Chen et al. [36]. That of interface predicts the experimental observations of Chen et al. [36] with a rather low accuracy, in turn, the proposed curve for joint core closely characterizes the experimental observations of Chen et al. [36]. The trend obtained for the joint core is best among all data in reproducing the experimental observations of Chen et al. [36].

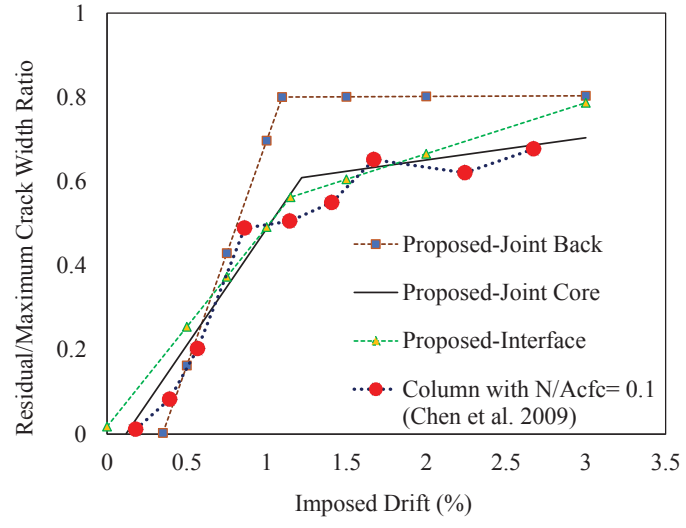

Data retrieved from Chen et al. [36]

Figure 5. Comparison of residual to imposed crack width ratio 


\section{COMMENTS ON REPAIRABILITY}

The apparent macroscopic damage at RC components, which covers wide cracks, the onset of concrete spalling, and local concrete crushing, is usually associated to the repairability threshold. Proper repair actions can restore the strength and stiffness of the component that experienced such a damage level. A comprehensive literature review of codes, standards, and guidelines $[30,37]$ showed a high scatter in the definition of the repairability threshold. FEMA P-58 [30] refers to DS1 (with corresponding maximum drift ratio of $1.75 \%$ ) for non-conforming beam-column joints (under the condition that residual crack width is smaller than $1.50 \mathrm{~mm}$ ) while HAZUS MR4 [37] associates the imposed drift with $0.60 \%$ for moderate structural damage. Besides, FEMA P-58 [30] also refers to residual drift ratio of $0.5 \%$ for the repairability threshold. As mentioned previously, the residual drifts of $0.35 \%$ and $0.75 \%$ are the closest values to $0.5 \%$ residual drift ratio representing the threshold limit as per FEMA P58 [30]. The imposed drifts are $1.00 \%$ and $1.50 \%$, respectively. The change in the curve characteristics lies between imposed drifts of $1.00 \%$ and $1.50 \%$, corresponding to the threshold value of residual drifts in FEMA P-58 [30] (Figure 6). To conclude, the breakpoint of the curve where it changes the characteristics can be assumed as a feasible repairability threshold value, which is between $1.00 \%$ and $1.50 \%$ imposed drift.

The correlated most important EDPs, which are residual and maximum crack width, allows the calculation of the maximum crack width. The maximum crack width can be calculated by the proposed curves if the residual crack width (which is a quantifiable parameter after an earthquake) and maximum inter-story drift (which can be estimated with a numerical model) are known. It should be also noted that this study relies on the numerical and stochastic assessment of the substandard beam-column joint. The specimen represents the substandard RC member with low strength concrete and plain round bar. The scatter in the stochastic analysis is considered only for material uncertainties. Besides, the resulting failure mode is shear failure together with slippage of the beam longitudinal reinforcement. A further study is required accounting for geometrical uncertainties together with different failure modes.

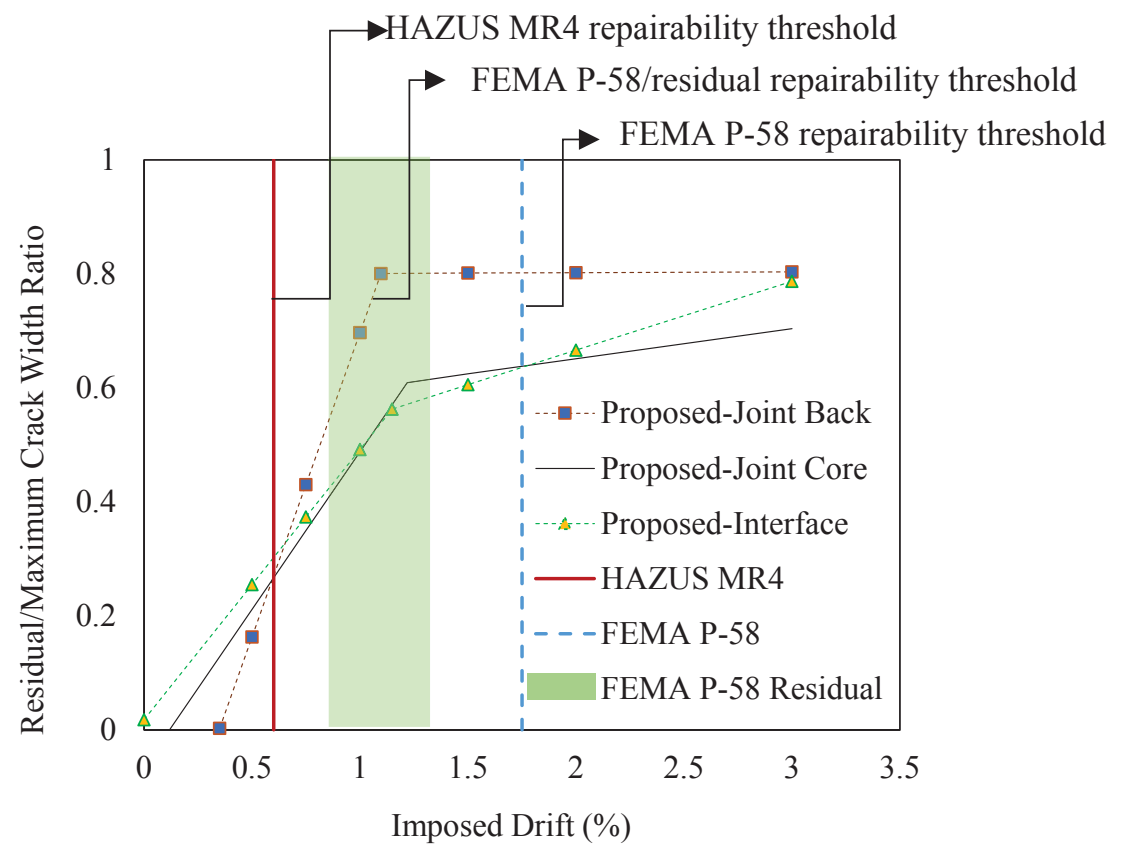

Figure 6. Repairability thresholds on residual-to-maximum crack width plots 


\section{CONCLUSION}

Existing reinforced concrete buildings are vulnerable to seismic actions due to lack of earthquake-resistant design detailing. The poor energy dissipation and sudden strength and stiffness degradation may result in devastating brittle failure for beam-column joints. Furthermore, the lack of transverse reinforcement does not allow to keep the integrity of joint panel, often resulting in marked cracking difficult to repair. Determining widely recognized acceptance criteria for feasible repair is challenging. Limiting the residual drift is commonly accepted since it is a measurable quantity after an earthquake (i.e., the residual story drift and so residual crack). On the other hand, the maximum inter-story drift allows making proper consideration on the achieved damage state by using available fragility curves. However, this requires a reliable numerical model. Based on the results of numerical analyses by using a validated numerical FEM model, this study proposes a correlation between residual and maximum crack width as well as evaluation of both maximum and residual crack width.

Based on the obtained results, the following preliminary conclusions can be drawn;

- The reliability of setting a crack repairability limit based on the residual drift (and so crack width) is validated via the correlation between the residual crack widths and maximum crack widths.

- The data fitted with a linear relationship has enough accuracy. The correlation among datasets (i.e., imposed/residual drift and imposed/residual crack width), referred as the coefficient of determination $R^{2}$ in the graphs, is high demonstrating an acceptable level of accuracy of the data fitting at $1.00 \%$ and $1.50 \%$ imposed drifts corresponding to $0.35 \%$ and $0.75 \%$ residual drifts, respectively. Those are the closest values to $0.5 \%$ which is considered a feasible threshold value for repair according to FEMA P-58 [30].

- The residual-to-maximum crack width ratio graphs allow to draw important consideration on the feasible repairability and crack closure effect for RC beam-column joints. The change of steepness approximately takes place between $1.00 \%$ and $1.50 \%$ imposed drift. With the less steep curve, the residual-to-maximum crack width ratio gets close to 1.00. Namely, the cracks become large enough, which are not closing, and exhibit large residual cracks. Therefore, the breakpoint of the curve where it changes the characteristics can be assumed as the feasible repairability threshold value.

- The study relies on the numerical and stochastic assessment of the substandard beamcolumn joint with low strength concrete and plain round bar. The shear failure together with slippage of the beam longitudinal reinforcement is the resulting failure mode. A further study is required accounting for geometrical uncertainties together with different failure modes.

\section{ACKNOWLEDGMENTS}

This study was performed within the framework of the PE2019-2021 joint program DPCReLUIS. Also, it was accomplished with the support of the Educational and Research Centre in Transport, Faculty of Transport Engineering, University of Pardubice.

\section{REFERENCES}

[1] Pampanin, S., Christopoulos, C., Chen, T.-H., Development and validation of a metallic haunch seismic retrofit solution for existing under-designed RC frame buildings. Earthquake Engineering \& Structural Dynamics, 35, 2006. 
[2] Bedirhanoglu, I., Ilki, A., Pujol, S., Kumbasar, N., Seismic behavior of joints built with plain bars and low-strength concrete. ACI Structural Journal, 2010.

[3] Yurdakul, Ö., Avşar, Ö., Strengthening of substandard reinforced concrete beam-column joints by external post-tension rods. Engineering Structures, 107, 2016.

[4] Yurdakul, Ö., Tunaboyu, O., Avşar, Ö., Retrofit of non-seismically designed beam-column joints by post-tensioned superelastic shape memory alloy bars. Bulletin of Earthquake Engineering, 16, 2018.

[5] Del Vecchio, C., Di Ludovico, M., Balsamo, A., Prota, A., Seismic retrofit of real beamcolumn joints using fiber-reinforced cement composites. Journal of Structural Engineering, 144, 2018.

[6] Hassan, W.M., Moehle, J.P., Shear strength of exterior and corner beam-column joints without transverse reinforcement. ACI Structural Journal, 115, 2018.

[7] De Risi, M.T., Del Vecchio, C., Ricci, P., Di Ludovico, M., et al., Light FRP strengthening of poorly detailed reinforced concrete exterior beam-column joints. J. Compos. Constr., 24, 2020.

[8] Haach, V.G., Lúcia Homce De Cresce El Debs, A., Khalil El Debs, M., Evaluation of the influence of the column axial load on the behavior of monotonically loaded R/C exterior beam-column joints through numerical simulations. Engineering Structures, 30, 2008.

[9] Kulkarni, S.A., Li, B., Yip, W.K., Finite element analysis of precast hybrid-steel concrete connections under cyclic loading. Journal of Constructional Steel Research, 64, 2008.

[10] Del Vecchio, C., Di Ludovico, M., Prota, A., Manfredi, G., Modelling beam-column joints and FRP strengthening in the seismic performance assessment of RC existing frames. Composite Structures, 142, 2016.

[11] Najafgholipour, M.A., Dehghan, S.M., Dooshabi, A., Niroomandi, A., Finite element analysis of reinforced concrete beam-column connections with governing joint shear failure mode. Latin American Journal of Solids and Structures, 14, 2017.

[12] Yurdakul, Ö., Del Vecchio, C., Di Ludovico, M., Avsar, Ö., Numerical simulation of substandard beam-column joints with different failure mechanisms. Structural Concrete, 2020.

[13] Yurdakul, O., Del Vecchio, C., Di Ludovico, M., Routil, L., et al., Sensitivity of cyclic response of substandard beam-column joints to material properties, in: Computational Methods in Structural Dynamics and Earthquake Engineering (COMPDYN 2019), Crete, Greece., 2019.

[14] Yurdakul, Ö., Tunaboyu, O., Routil, L., Avşar, Ö., Parameter sensitivity of CFRP retrofitted substandard joints by stochastic computational mechanics. Composite Structures, 238, 2020.

[15] Shayanfar, J., Hemmati, A., Bengar, H.A., A simplified numerical model to simulate RC beam-column joints collapse. Bull Earthquake Eng, 17, 2019.

[16] El-Amoury, T., Ghobarah, A., Seismic rehabilitation of beam-column joint using GFRP sheets. Engineering Structures, 24, 2002.

[17] Ilki, A., Bedirhanoglu, I., Kumbasar, N., Behavior of FRP-retrofitted joints built with plain bars and low-strength concrete. Journal of Composites for Construction, 15, 2011.

[18] Sezen, H., Repair and Strengthening of Reinforced Concrete Beam-Column Joints with Fiber-Reinforced Polymer Composites. J. Compos. Constr., 16, 2012.

[19] Garcia, R., Pilakoutas, K., Hajirasouliha, I., Guadagnini, M., et al., Seismic retrofitting of RC buildings using CFRP and post-tensioned metal straps: shake table tests. Bulletin of Earthquake Engineering, 15, 2017. 
[20] Faleschini, F., Gonzalez-Libreros, J., Zanini, M.A., Hofer, L., et al., Repair of severelydamaged RC exterior beam-column joints with FRP and FRCM composites. Composite Structures, 207, 2019.

[21] Del Vecchio, C., Eeri, M., Di Ludovico, M., Prota, A., Repair costs of RC building components: From actual data analysis to calibrated consequence functions. Earthquake Spectra, 36, 2020.

[22] Yurdakul, O., Avsar, O., Structural repairing of damaged reinforced concrete beam-column assemblies with CFRPs. Structural Engineering and Mechanics, 54, 2015.

[23] JBDPA, Guideline for post-earthquake damage evaluation and rehabilitation, The Japan Building Disaster Prevention Association (JBDPA), Japan, 2001.

[24] fib, Displacement-based seismic design of reinforced concrete buildings. State-of-art report. Fédération Internationale du Béton (fib), fib Bulletin No. 25. Lausanne, Switzerland., 2003.

[25] European Commission \& Joint Research Centre, Field Manual for post-earthquake damage and safety assessment and short-term countermeasures (AeDES), Institute for the Protection and Security of the Citizen, Joint Research Centre, European Commission, 2007.

[26] Cardone, D., Fragility curves and loss functions for RC structural components with smooth rebars. Earthquakes and Structures, 10, 2016.

[27] FEMA 306, Evaluation of earthquake damaged concrete and masonry wall buildings: Basic procedures manual (FEMA 306), Federal Emergency Management Agency, USA, 1998.

[28] Pagni, C.A., Lowes, L.N., Fragility functions for older reinforced concrete beam-column joints. Earthquake Spectra, 22, 2006.

[29] Di Ludovico, M., Polese, M., Gaetani d'Aragona, M., Prota, A., et al., A proposal for plastic hinges modification factors for damaged RC columns. Engineering Structures, $\mathbf{5 1}, 2013$.

[30] FEMA P58, Seismic performance assessment of buildings (FEMA P58), Federal Emergency Management Agency, USA, 2018.

[31] Marder, K., Elwood, K.J., Motter, C.J., Clifton, G.C., Post-earthquake assessment of moderately damaged reinforced concrete plastic hinges. Earthquake Spectra, 36, 2020.

[32] TBI, Guidelines for Performance - Based Seismic Design of Tall Buildings, Version 2.03, Pacific Earthquake Engineering Center Report No. 2017/06, 2017.

[33] ATENA Program Documentation, Part 8., User's manuel for ATENA-GID interface, 2015.

[34] Pukl, R., Sajdlova, T., Routil, L., Novák, D., et al., Case study - Nonlinear reliability analysis of a concrete bridge., in: Maintenance, Monitoring, Safety, Risk and Resilience of Bridges and Bridge Networks: Proceedings of the 8th International Conference on Bridge Maintenance, Safety and Management (IABMAS2016), 2016.

[35] Joint Committee on Structural Safety, Probabilistic model code, Part 3: Material properties, https://www.jcss-lc.org/, 2000.

[36] Chen, L., Lu, X., Jiang, H., Zheng, J., Experimental investigation of damage behavior of RC frame members including non-seismically designed columns. Earthq. Eng. Eng. Vib., 8, 2009.

[37] HAZUS MR4, Multi-hazard loss estimation methodology. Earthquake Model (HAZUS MH. MR4) Technical Manual. Department of Homeland Security, Emergency Preparedness and Response Directorate, FEMA, 2003. 